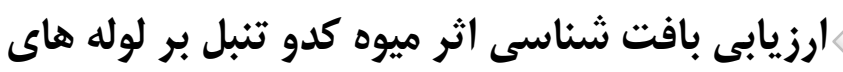

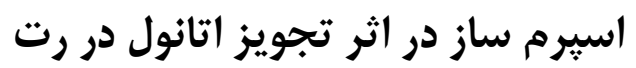

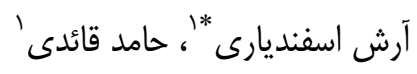

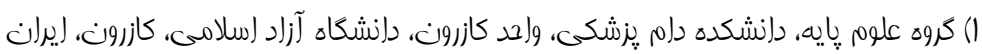

\author{
تاريخ دريافت:
}

مقدمه: بنا بر تحقيقات كذشته، كدو تنبل هورمون هاى جنسى را در جنس نر افزايش مى دهد. هدف از اين تحقيق بررسى اثرات كدو تنبل بر

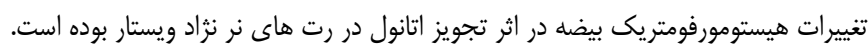

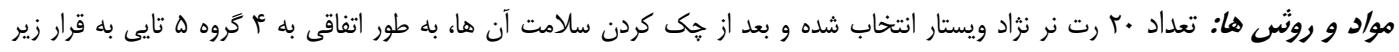

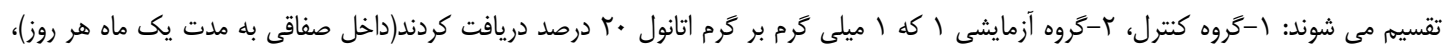

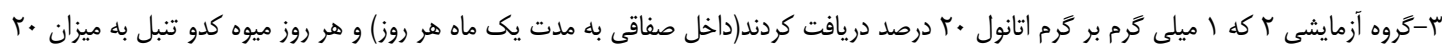

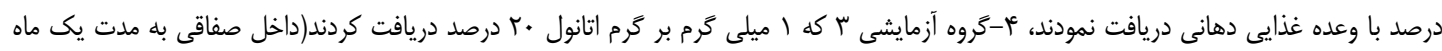

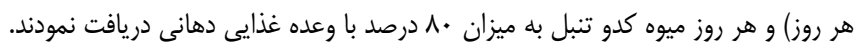

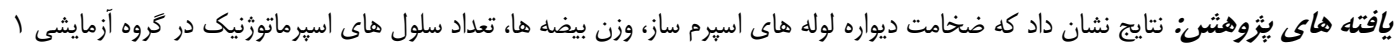

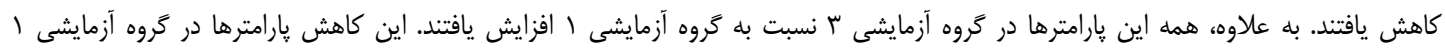

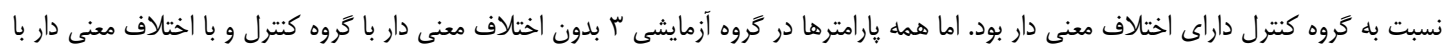
كروه آزمايشى ا افزايش داشته است.

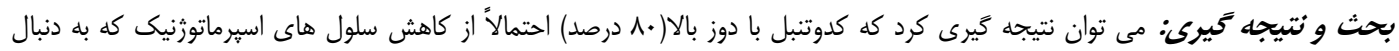

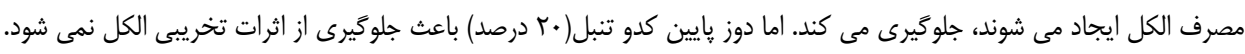

Email: Esfandiari.arash@gmail.com

Copyright (C) 2018 Journal of Ilam University of Medical Science. This is an open-access article distributed under the terms of the Creative Commons Attribution international 4.0 International License (https://creativecommons.org/licenses/by-nc/4.0/) which permits copy and redistribute the material, in any medium or format, provided the original work is properly cited. 
آ، سى و ای، يتاسيه، كلسيه، فسفر، منيزيم و... هم آنمئ

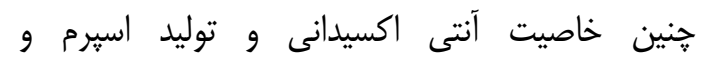
تستوسترون مى تواند سبب افزايش اسيرماتوزنز و توليد

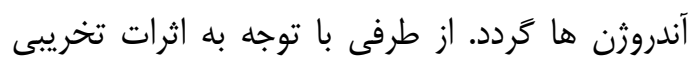

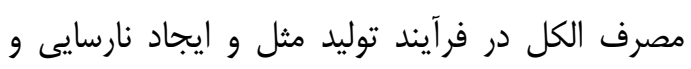
مرى سلول هاى جنسى، مورفولوزى ناقص اسيرم ها،

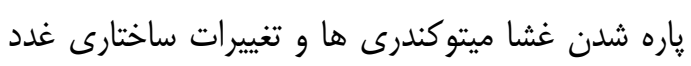

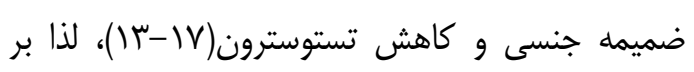
آن شديم كه در تحقيق حاضر با مصرف الكل و ايجاد

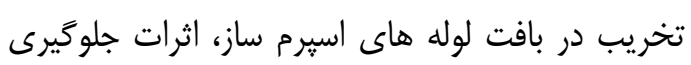

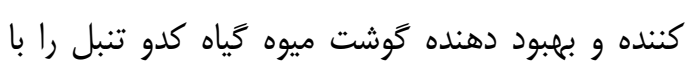

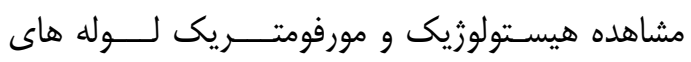

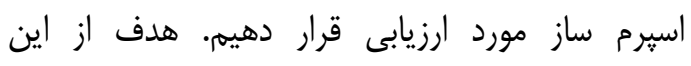

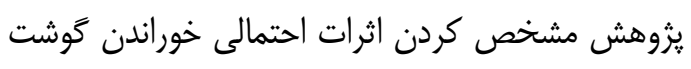

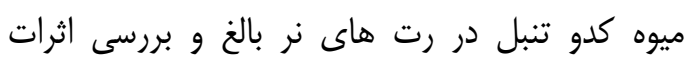

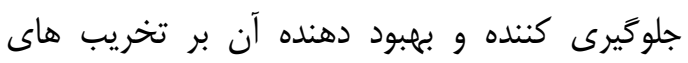

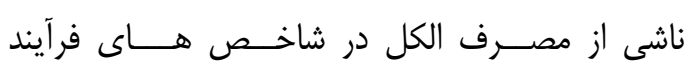

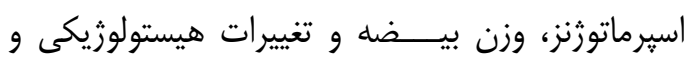
هيستومورفومتريكى لوله هاى اسيرم ساز مى باشد تا در

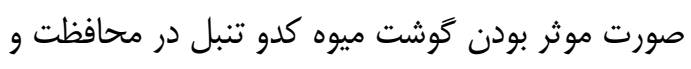

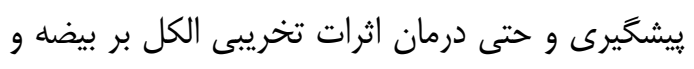

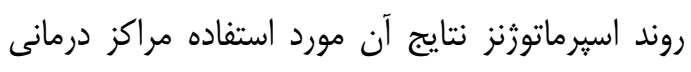
آندوكرينى و توليد مثلى قرار گيرد.

\section{مواد و روش ها ناني}

در اين تحقيق • r سر رت نر بالغ نزاد ويستار با سن

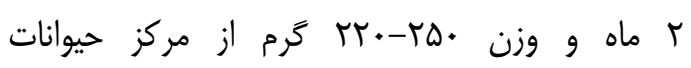
آزمايشگاهى دانشكاه علوم يزشكى شيراز تهييه كَرديدند.

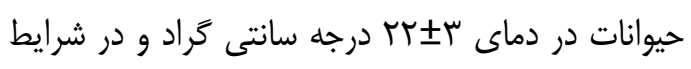

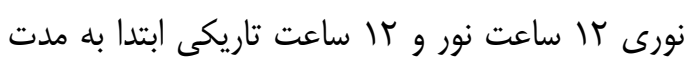

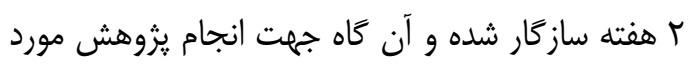

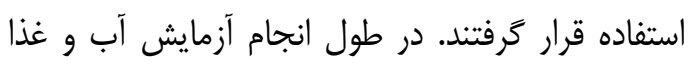

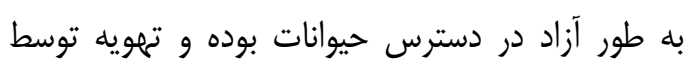

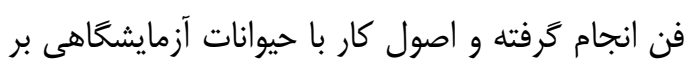

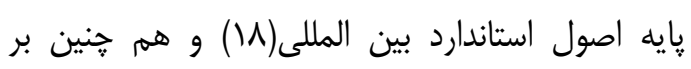

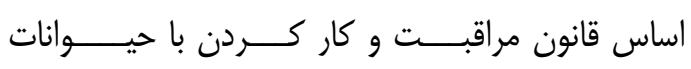

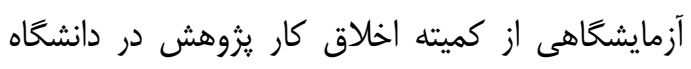
آزاد اسلامى واحد كازرون رعايت كَرديد. بعد از مشاهده
مقدمه - مقه كياهان دارويى از منابع طبيعى مهم دنيا به شمار

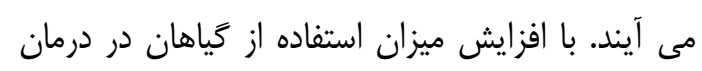

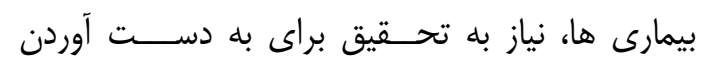

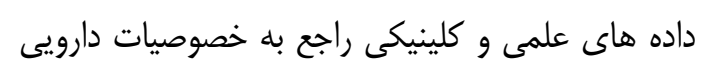

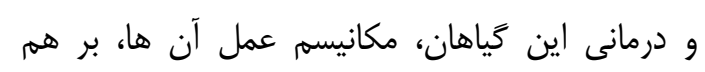

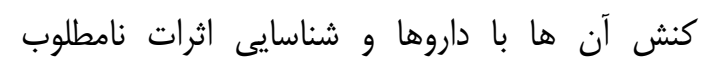

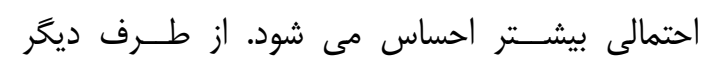

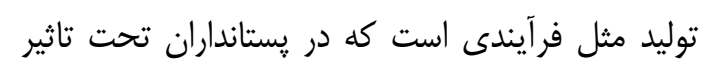
محورهاى عصبى و هورمونى متعددى قرار دارد. اهميت

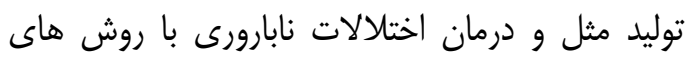

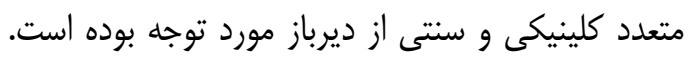

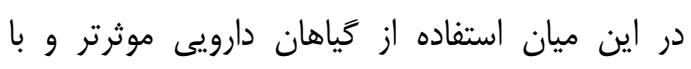
موفقيت هايى همراه بوده است. در اين ميان كدو تنبل

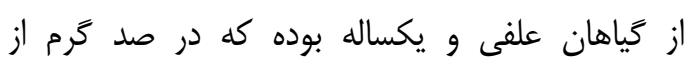

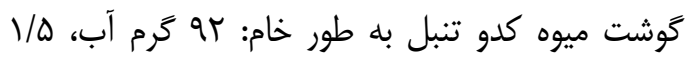

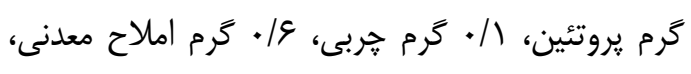

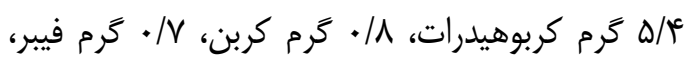

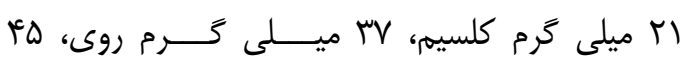

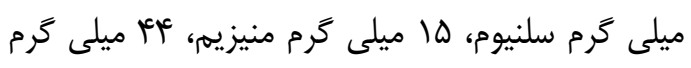

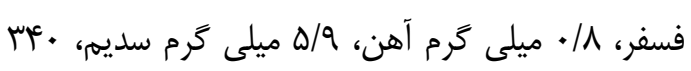

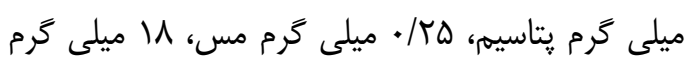

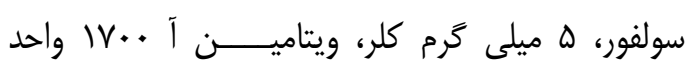

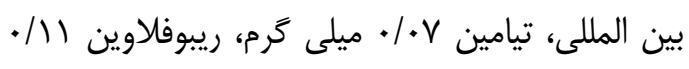

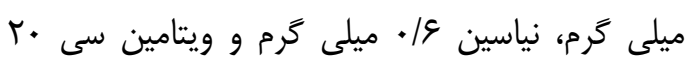

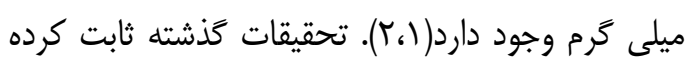

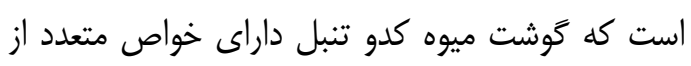
جمله جلوكيرى از زخم معده، ضد آنمى، كاهش

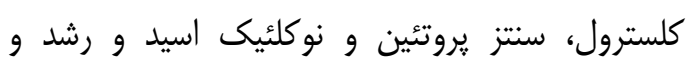

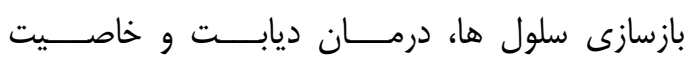

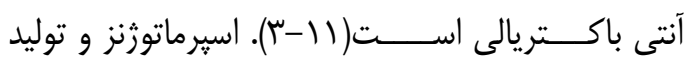
أندروثن از عملكردهاى بيضه بودها، كه در اين ميان

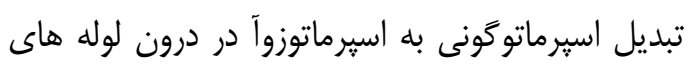
اسبرم ساز صورت مى گيرد. هم تِنين توليد آندروثن توسط سلول هاى بينابينى در بين لوله هاى اسبرم ساز

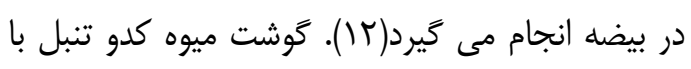
توجه به وجود اسيدهاى هرب غير اشباع، ويتامين هاى 
مino-Eye- مقاطع بافتى توسط دوربين مخصوص AM 423

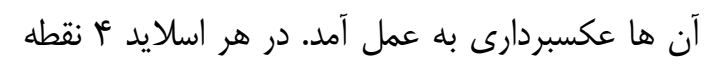

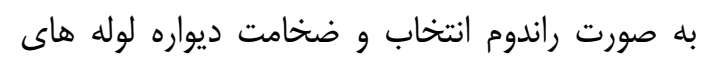

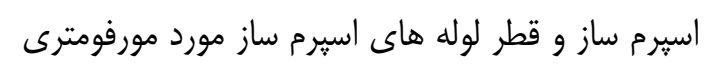

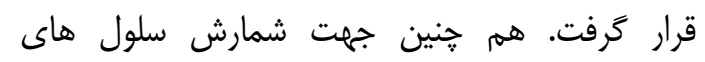

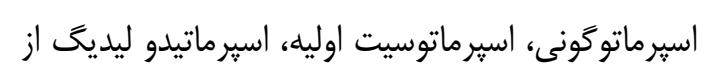

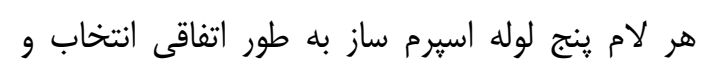

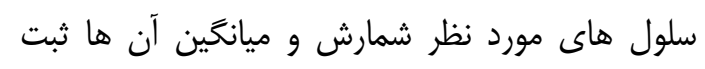

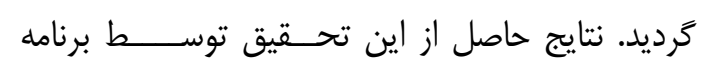

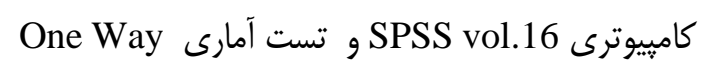
ANOVA آمارى قرار كرفت(P

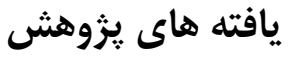

نتايج نشان دادند كه ميانگين وزن بئن بيضه راست و واست

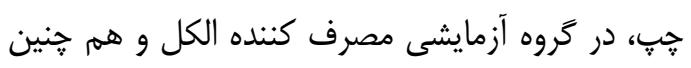

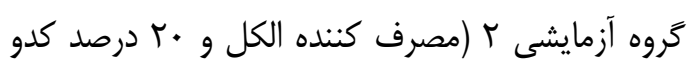

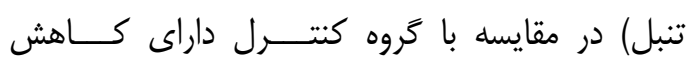

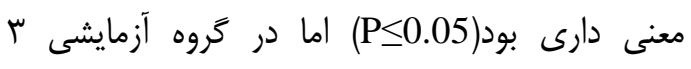

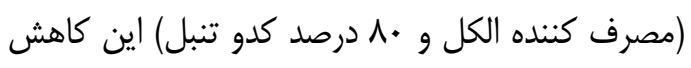
جبران شده و فاقد اختاف معنى دار با كروه كنترل

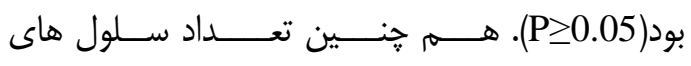

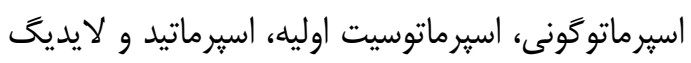

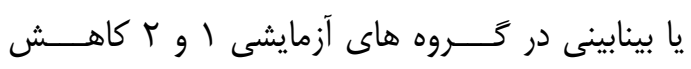
معنى دارى نسبت به گروه كنترل داشته(

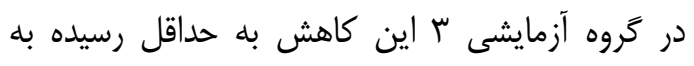

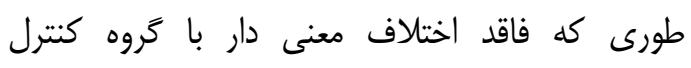

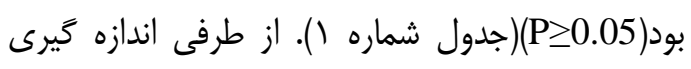

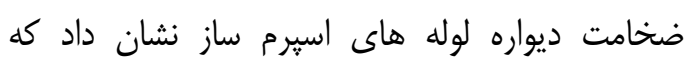

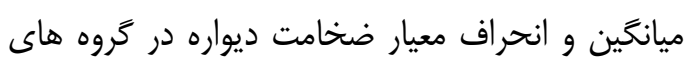

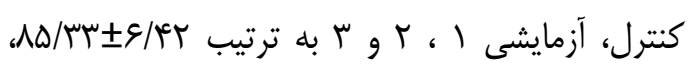
بو بود. هم جنين ميانخين قطر لوله هاى اسبرم ساز و

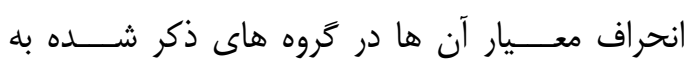
ترتيب V/

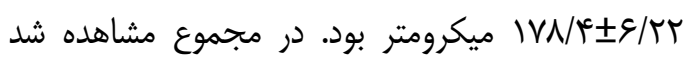

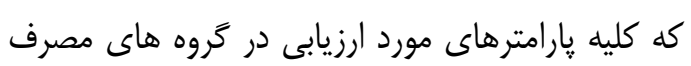

سلامت عمومى حيوانات به جهار كروه ينج تايى به

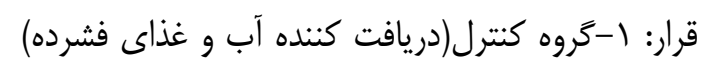

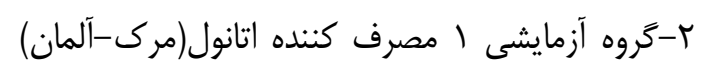

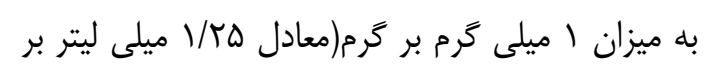

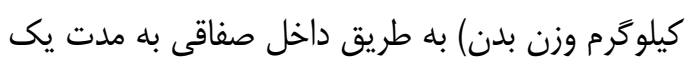

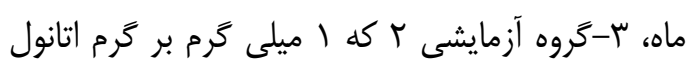

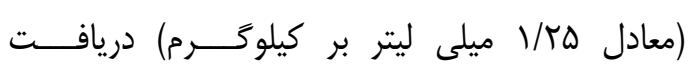

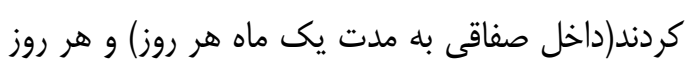

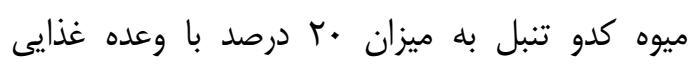

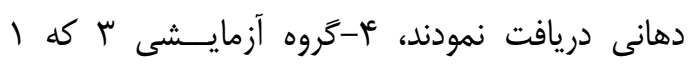

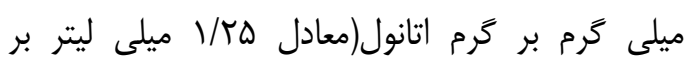

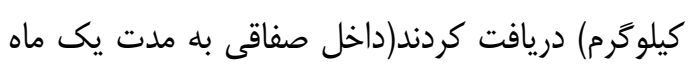

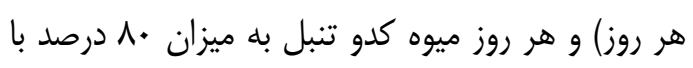

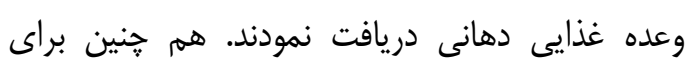

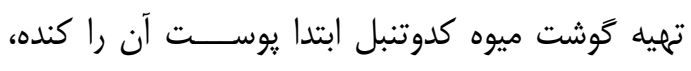

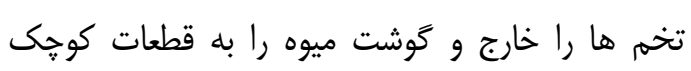

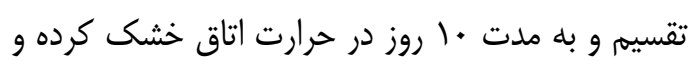

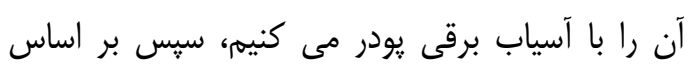

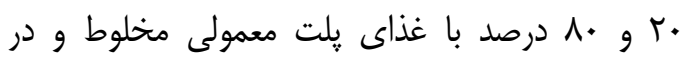

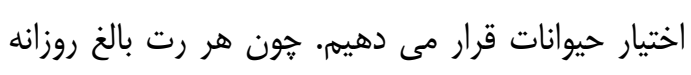

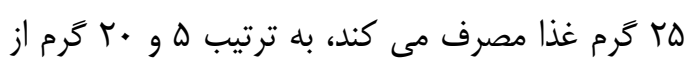
غذاى مورد نظر را يودر ميوه كدو تنبل انتخاب كرده و

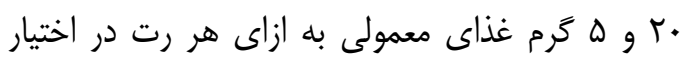

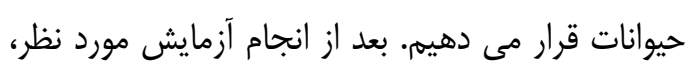

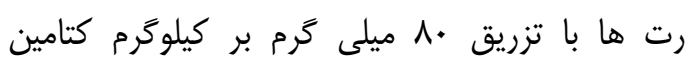

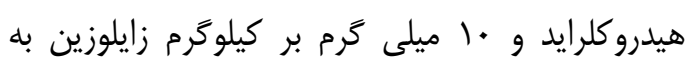
طريق داخل صفاقى بيهوش و از طريق شكاف ناف نائ ناحيه

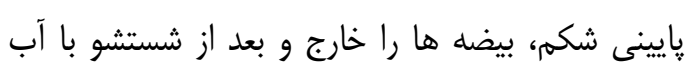

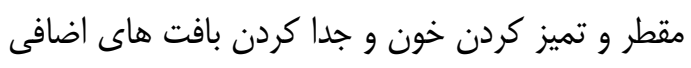

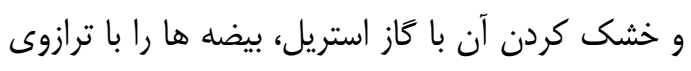

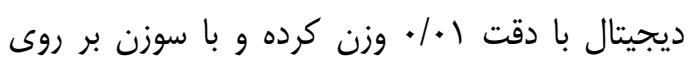

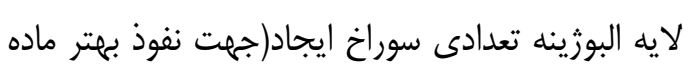

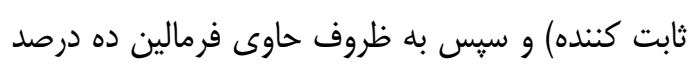

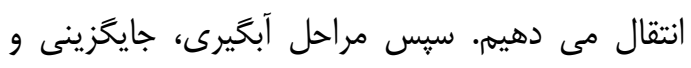

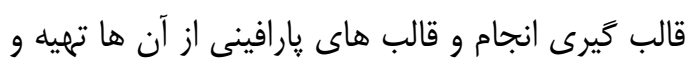

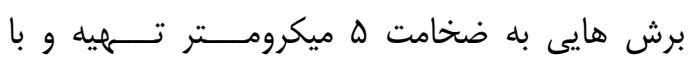

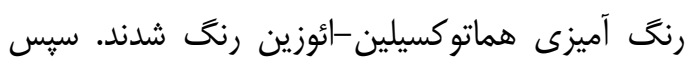




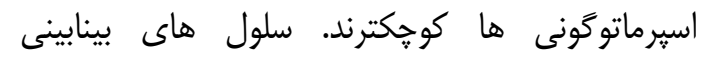
(لايديخ) نيز در فضاى ميان لوله هاى اسيرم ساز قرار

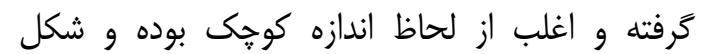
كروى يا بيضوى دارند. هسته در اين سلول ها قابل

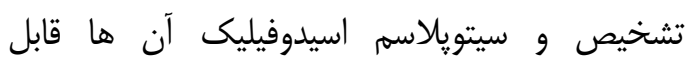

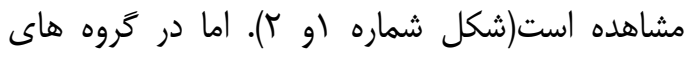

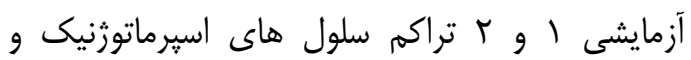

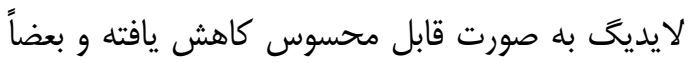
در بين اين سلول ها واكوئل هايى نيز مشائ مشاهده

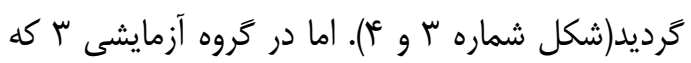

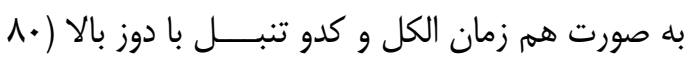

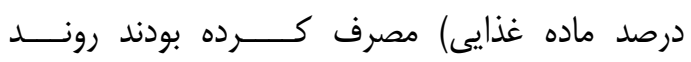

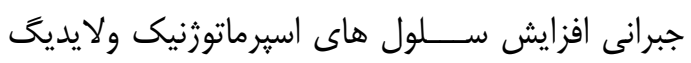

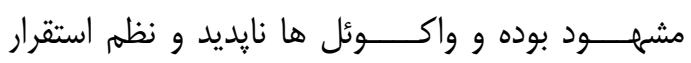
سلول ها به حالت طبيعى برگَـــــــهـ بود(شكل شماره
كننده الكل و مصرف كننده الكل و دوز يايين كدو

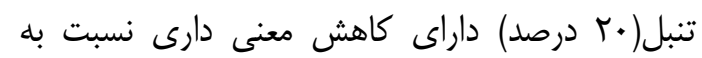

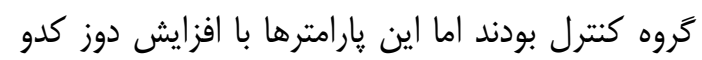

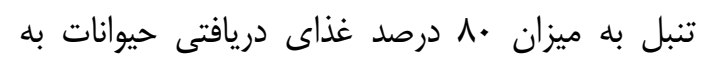

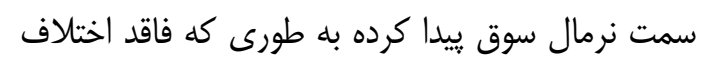

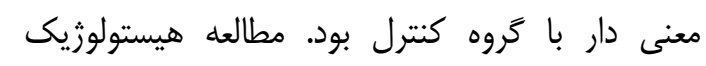
مقاطع لوله هاى اسيرم ساز نيز تاييدكننده مطالعات

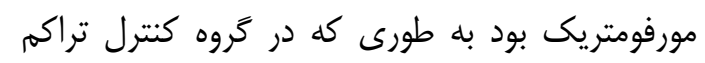

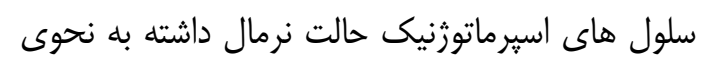
كه سلول هاى اسيرماتوگُونى شكل تقريباً كروى داشته و اغلب بر روى غشاى پايه لوله هاى اسيرم ساز قرار

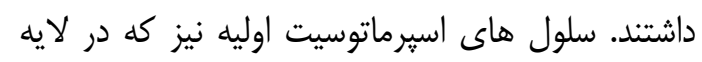

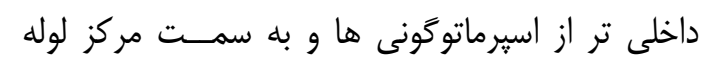

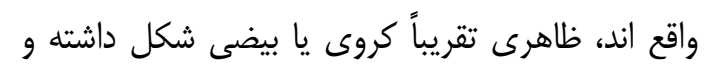
هسته كاملاً مشخص و دانع دانهدارى دارند. اسبرماتيدها

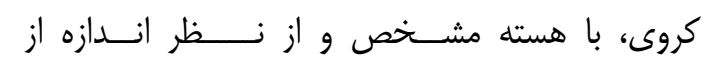

جدول شماره ا. ميانگَين و انحراف معيار وزن بيضه ها، تعداد سلول هاى اسِرماتوكَونى، تعداد سلول هاى اسيرماتوسيت اوليه،

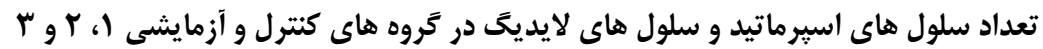

\begin{tabular}{|c|c|c|c|c|c|c|}
\hline 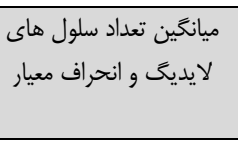 & ميانكين تعداد سلول هاى & 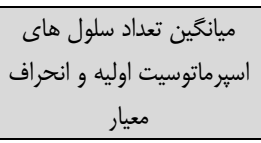 & 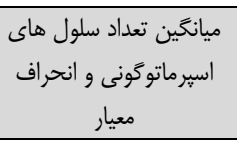 & ميانكين وزن بيضه وانحراف & $\begin{array}{c}\text { ميانكين وزن بيضه و انحراف } \\
\text { رعيار }\end{array}$ & \\
\hline $11 \pm 1$ & $199 / 99 \pm \% / 0$. & $\Lambda r \pm r$ & $9 q / 99 \pm r / \cdot 1$ & $1 / 0 \cdot \pm \cdot / 1 \cdot$ & $1 / \kappa \xi \pm \cdot / 1 \Delta$ & كروه كنترل \\
\hline$* / / 9 \Phi \pm r / \Delta)$ & * & 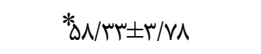 & * & $* / V 9 \pm \cdot / \cdot \Delta$ & $* / /{ }^{\mu} \pm \cdot / \cdot \Delta$ & كروه آزمايشى ا \\
\hline * $/ \& \varepsilon \pm \cdot / \Delta V$ & * & * & $* \psi \mid \psi / \xi \& \pm \cdot / \Delta V$ & $* / \Lambda \uparrow \pm \cdot / \cdot r$ & $* / \mathrm{V} A \pm \cdot / \mathrm{V}$ & كروه آزمايشى r \\
\hline $1 . / 99 \pm 1 / \Delta T$ & $\mid \Phi V / r r \pm r / \cdot \Delta$ & $v \wedge \pm r$ & $99199 \pm 1 / 19$ & $1 / x \pm 1$ & $1 / / \pm 1$ & كروه آزمايشى ؟ \\
\hline
\end{tabular}

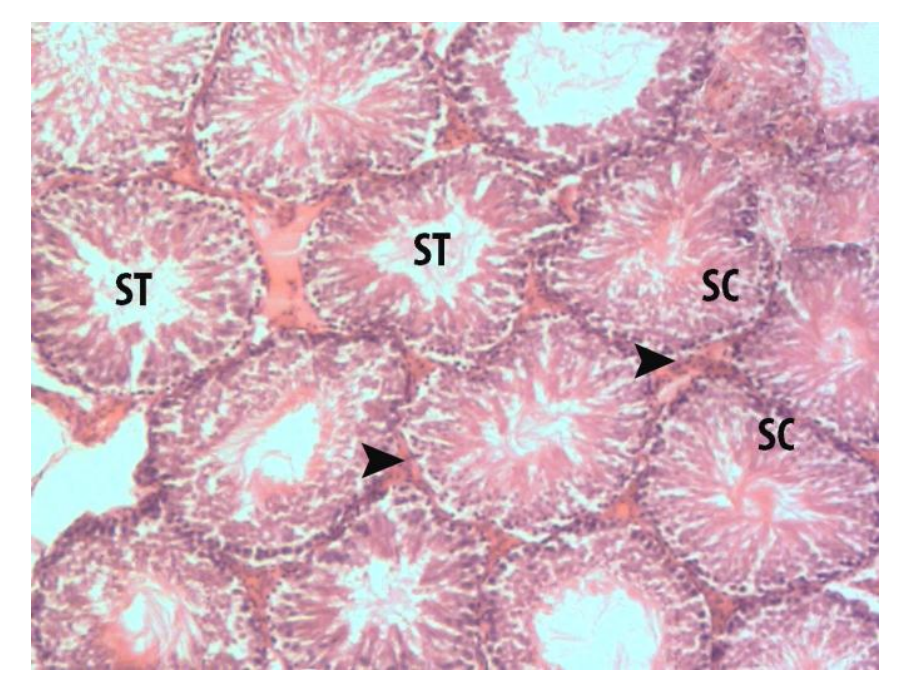

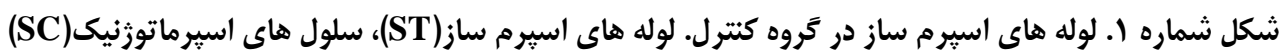

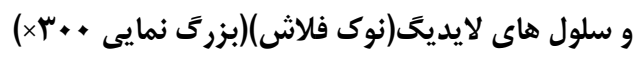



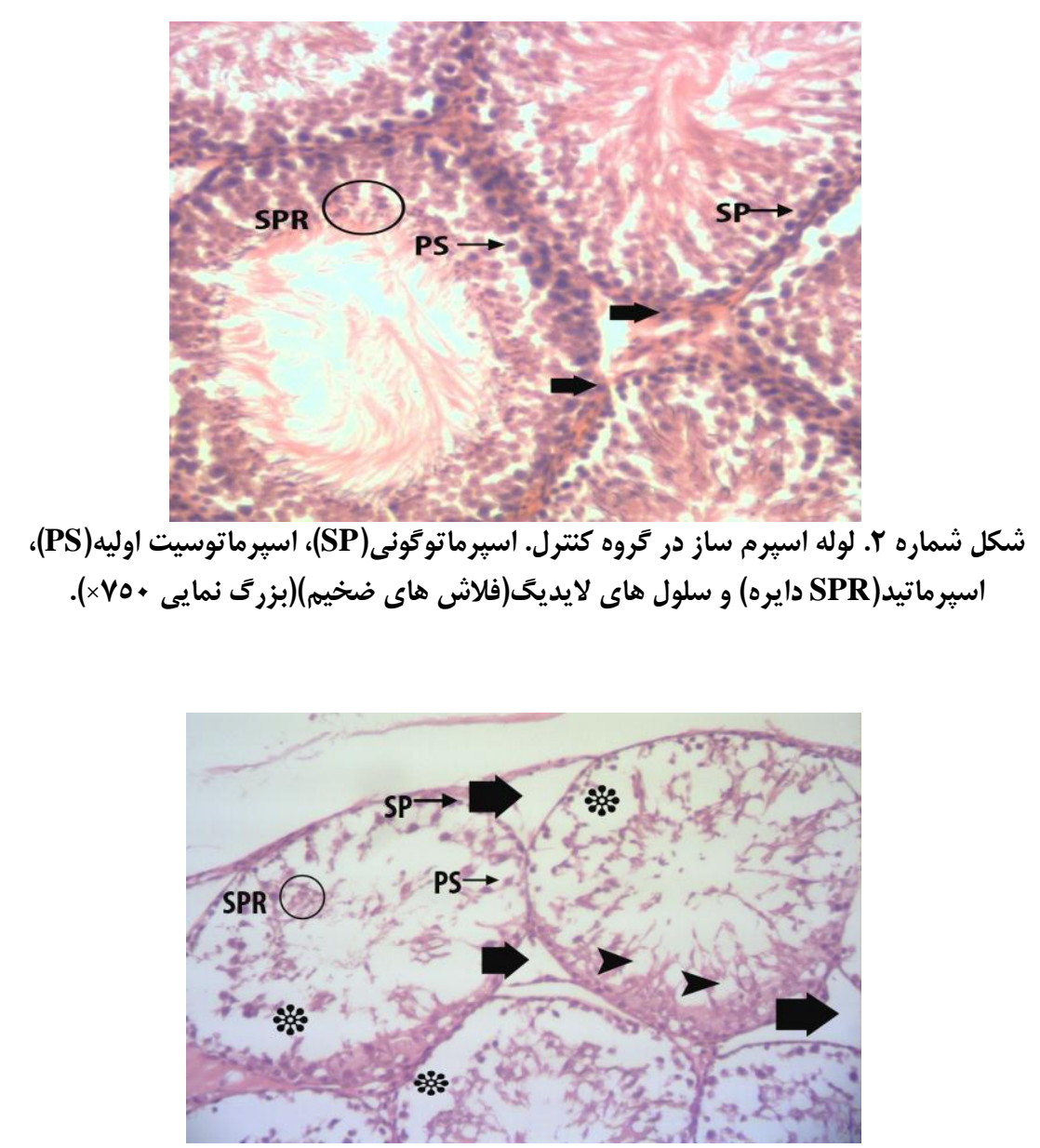

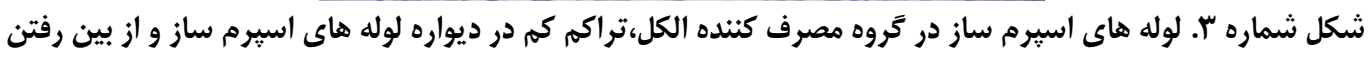

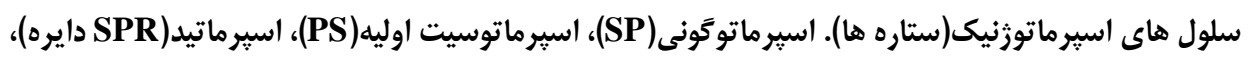

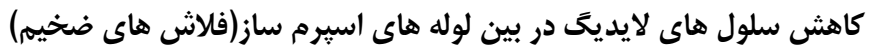

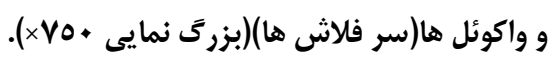

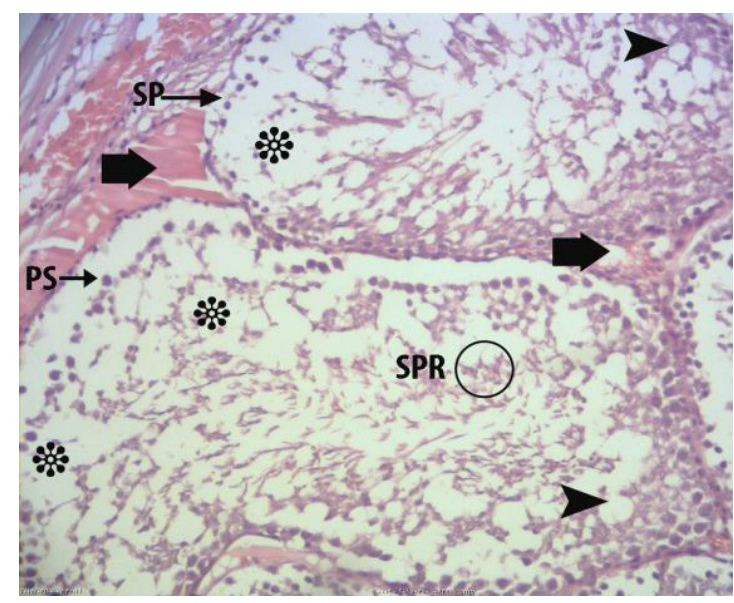

شكل شماره ع. لوله هاى اسبرم ساز در تروه مصرف كننده الكل و كدو تنبل + ب درصد،تراكم كم در ديواره لوله هاى اسبرم ساز

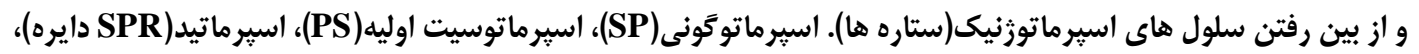

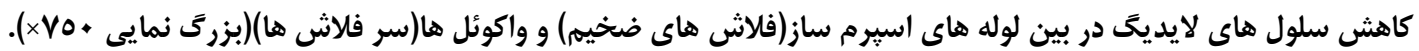




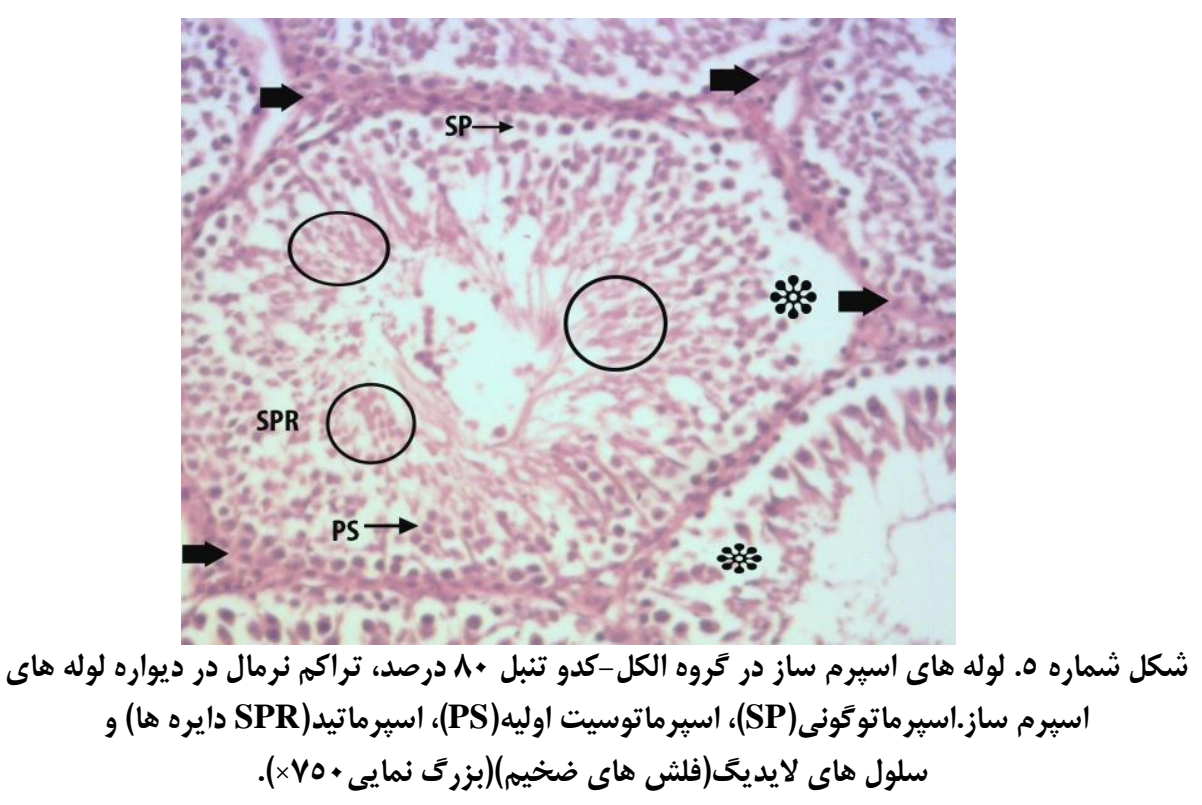

موجود در ميوه كياه كدو تنبل كه باعث افزايش تقسيم بحث و نتيجه كَيرى سلولى، بالا رفتن روند اسبرماتوزنز و افزايش تراكم

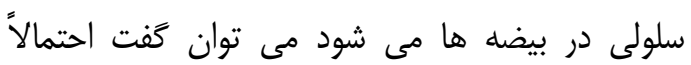

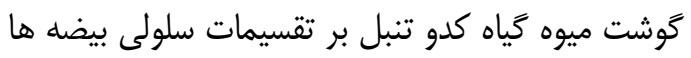

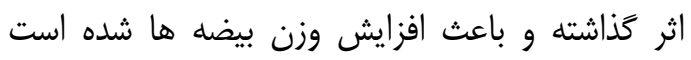
براى تكميل روند اسيرميوزنز نياز به افزايش كلسيه

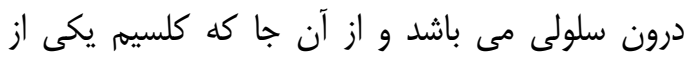

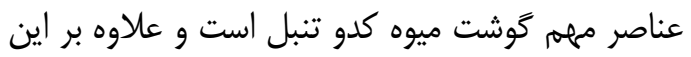
وجود فيبر موجود در گوشت ميوه كدو تنبل باعث كاصث افزايش جذب كلسيم مى شود. يس احتمال مى رود كه كوشت ميوه كدو تنبل باعث تشديد روند فئد اسبرماتوزنز

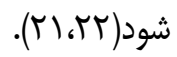
با توجه به وجود كلسيم در گوشت ميوه كدو تنبل و

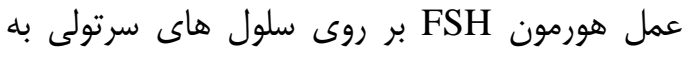

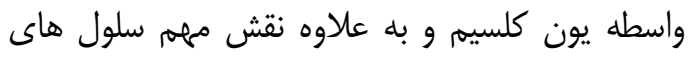
سرتولى در تغذيه اسبرم ها و روند اسبرماتوزنز، مى توان

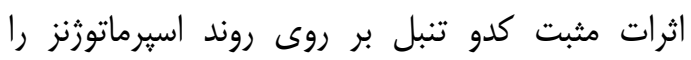

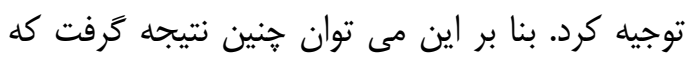

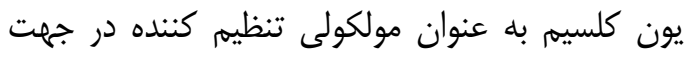
عملكرد سلول هاى سرتولى عمل كرده و علاوه بر اين

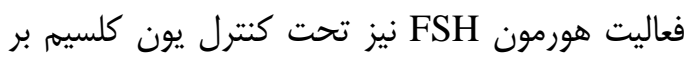

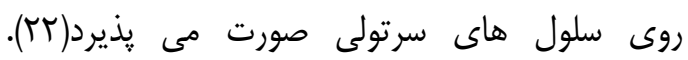

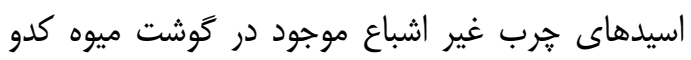
تغييرات هسيتولوزيك و مورفومتريك لوله هاى نئي

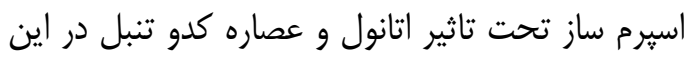

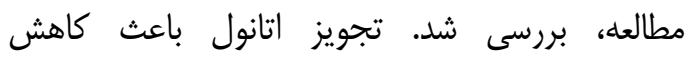
ضخامت ديواره لوله هاى اسبرم ساز، كاهش تعلد تعداد سلــول هاى اســــرماتــــوَّنى، اسيرماتويست اوليه،

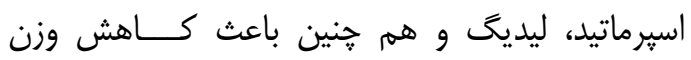

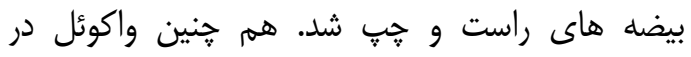

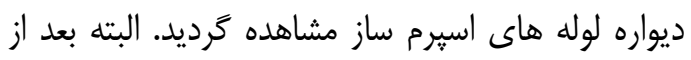

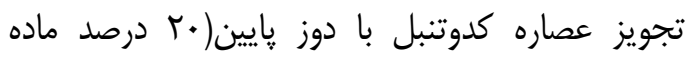
غزايى) و دوز بالا(•^ درصد ماده غذايى) مشاهدات

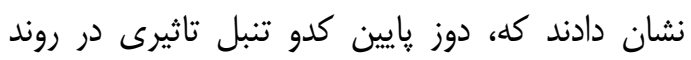
بهبود و يا جلوگيرى از آثار تخريبى الكل نداشته ولى دائل

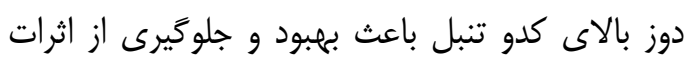

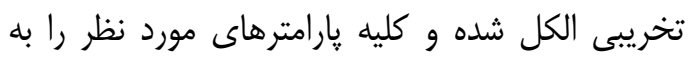

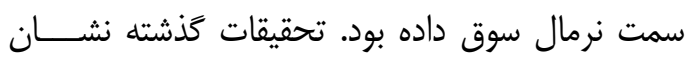

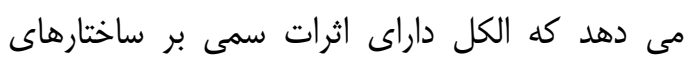

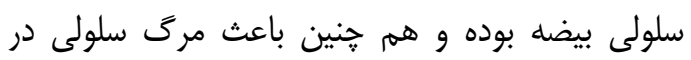

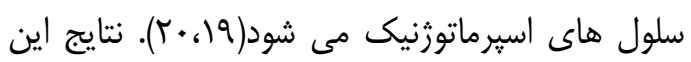

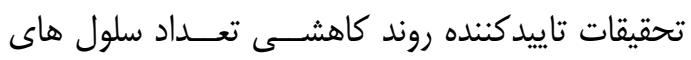

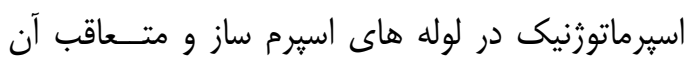
كاهش ضخامت ديواره اين لوله ها در تحقيق حاضر لهر مى باشد. به دليل وجود روى، كلسيه و ديخر تركيبات 
كه مى تواند نشانه كاهش استروييدوزنز باشد(·r). از

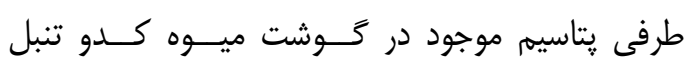
مى تواند سبب بلوى كردن كيرنده هاى بتا آدرنرزيك

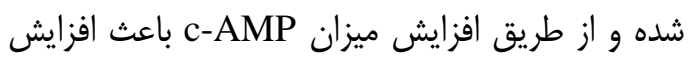

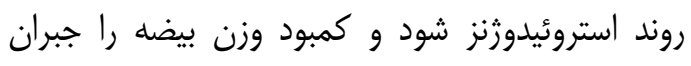

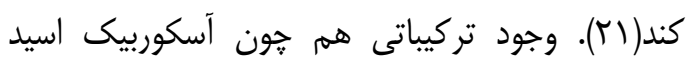

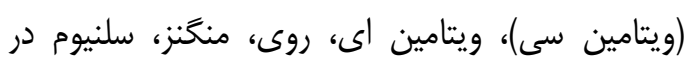

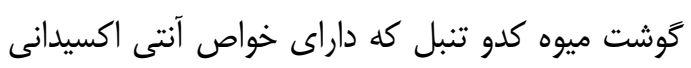

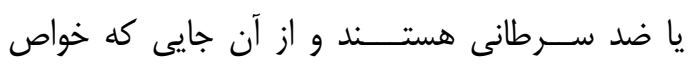

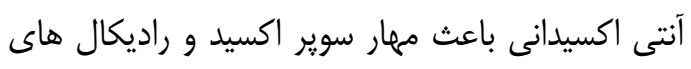

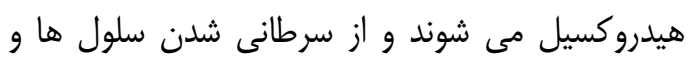

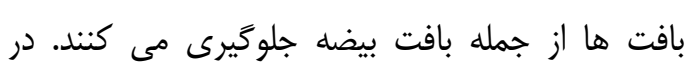

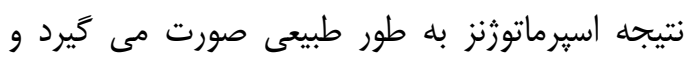
اختلالى در اين روند ايجاد نمى شود. از طرف دئ ديخر أنتى اكسيدان هاى قوى داراى اثرات شبه ويتامينى در إنى

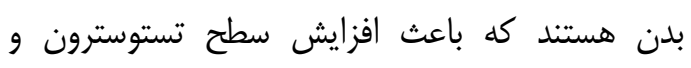

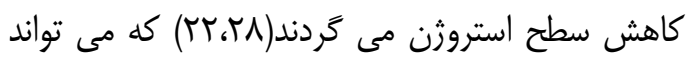
باعث تحريك اسيرماتوثنز شود. با مصرف كدو كن تنبل

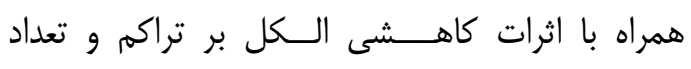
سلول هاى اسيرماتوزنيك مشاهده كرديد كه اين روند أند كاهشى جبران شده و به سمت نرمال سوق ييدا كرده است كه مى تواند به علت خاصيت آنتى اكسيدانى

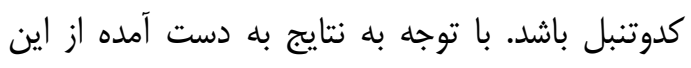
تحقيق مى توان اظهار كرد كه الكل باعث اثرات

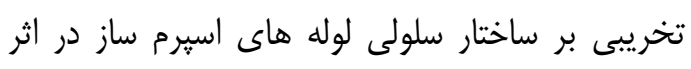
اكسيداتيو استرس شده و مشاهدات ميكروسكويى نشان داد كه مصرف عصاره كدوتنبل باعث بهبود اثرات

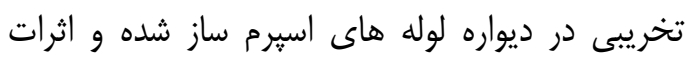

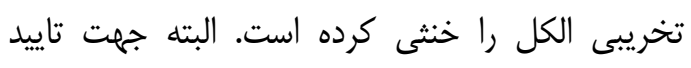

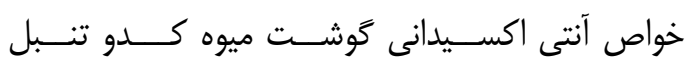
اندازه كيرى آنزيم هاى مربوطه جهت آني مطالعات آينده مئه ييشنهاد مى گردد. سياسگَزارى

از دانشخاه آزاد اســلامى واحد كازرون جهت

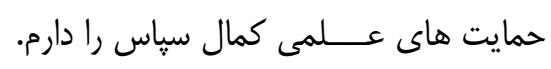

تنبل باعث مهار فعاليت ه-آلفا ردوكتازو از طرفى باعث فعاليت آنزيم Vا-بتا هيدروكسى استروئيد دهيدروزناز شده، از آن جا كه اين هورمون در توليد هيد هورمون النيد تستوسترون دخيل است، بنا بر اين احتمال مى رود كه ائ دون

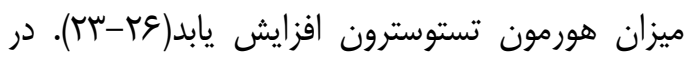

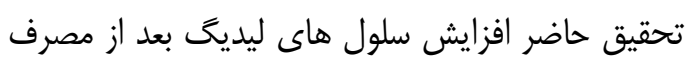

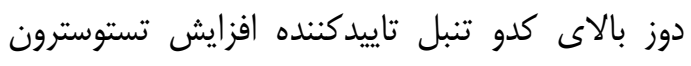

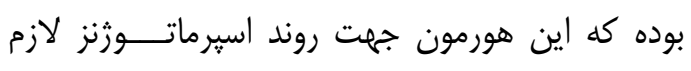

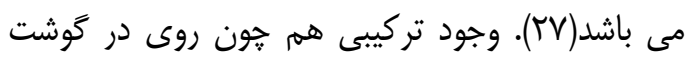

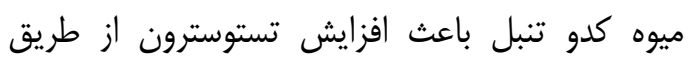

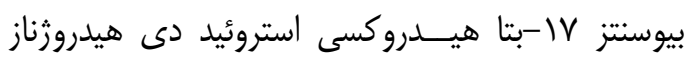

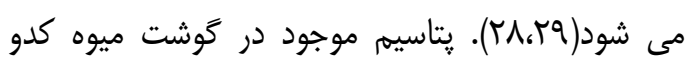

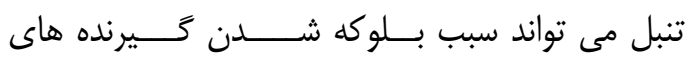

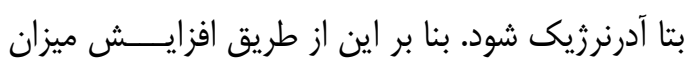

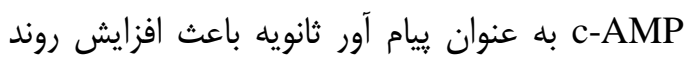

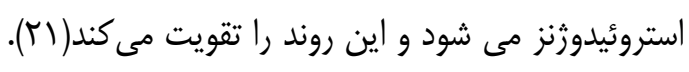

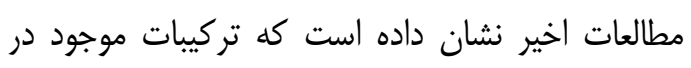

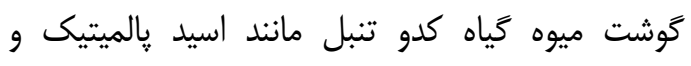

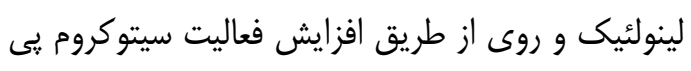

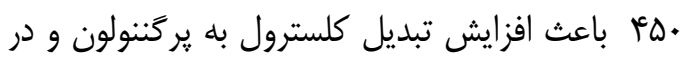

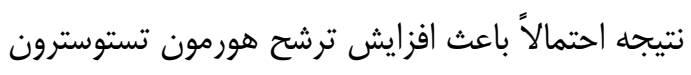

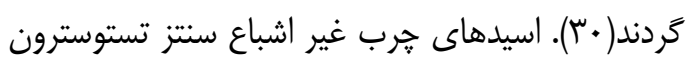

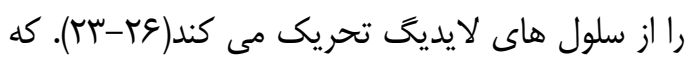

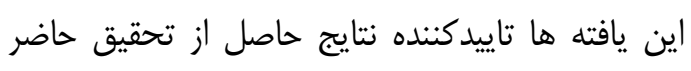

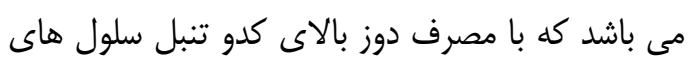

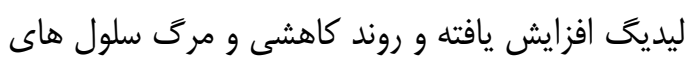

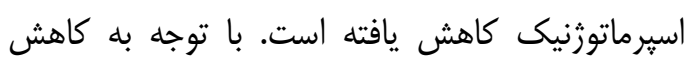

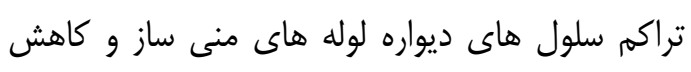

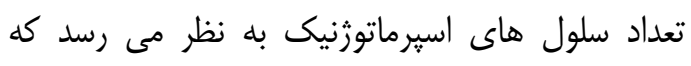

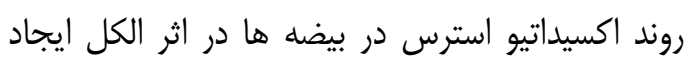

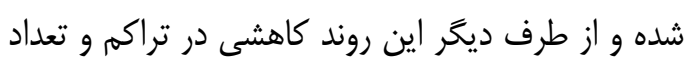

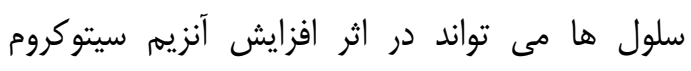

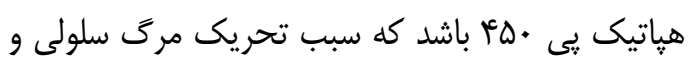

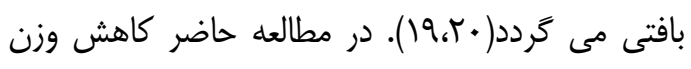
بيضه ها در گروه مصرف كنتده الكل مشاهده خـــرديد، 


\section{References}

1.Yong M, Ning H, Liu H. Exploitation and composition of pumpkin powder. Food Sci Technol 2006; 6: 299-301.

2.Caniço F, Ramalho M, Lima G, Quedas F. Study the evolution of texture and color Curcubita spp. postharvest and over time. J Food Technol Biotechnol Nut Portugal 2012; 13: 53-58.

3.Sentu S, Debjani G. Effect of ripe fruitpulp extract of cucurbita pepo Linn in aspirin induced gastric and duodenal ulcer in Rats. Ind J Exp Biol 2008; 46: 639-45.

4.Zhang Y, Shen X, Zhu L. The recent research development of natural hypoglycemic food pumpkin. Food Sci Technol 2002; 6: 68-70.

5.Bai X, Zhang X. Protective effect of compound pumpkin powder on diabetic Rats kidney. Herald Med 2006; 6: 616-7.

6.Jie S, Guoyou Y, Peng Du, Lanying C. Optimization of extraction technique of polysaccharides from pumpkin by response surface method. J Med Plants Res China 2011; 5: 2218-22.

7.Cunha A. Plantas e produtos vegetais em fitoterapia. $4^{\text {th }}$ ed. Fundacao Calouste Gulbenkian Publication. 2012; P.213.

8.Nkang A, Omokaro A, Egbe A, Amanke G. Variation of fatty acid proportion during desiccation of Telferia occidentalis seeds harvested at physiological and agronomic maturity. African J Biotechnol2003; 2:33-9. 9.Kazemi S, Asgari S, Moshtaghian SJ, Rafieian M, Mahzooni P. Preventive effect of pumpkin Cucurbita pepo 1. on diabetic index and histopathology of pancreas in alloxan-induced diabetes in Rats. J Isfahan Med Sch2011; 28: 872-81.

10.Akang EN, Oremosu AA, Dosumu OO, Noronha CC, Okanlawon AO. The effect of fluted pumpkin Telferia occidentalis seed oil ontestis and semen parameters. Agric Biol J N Am 2010; 1:697-703.

11. Mayor L, Moreira R, Sereno AM. Shrinkage, density, porosity and shape changes during dehydration of pumpkin .J Food Eng 2011; 103: 29-37. doi:10.1016/j.jfoodeng.2010.08.031

12.Rueysheng W, Shuyuan Y, Chiiruey T, Chawnshang C. Androgen receptor roles in spermatogenesis and fertility lessons from testicular cell specific androgen receptor knockout mice. Endocrine Rev 2009; 30:119-32. doi: 10.1210/er.2008-0025

13. Eid NA, Shibata MA, Ito Y, Kusakabe

$\mathrm{K}$, Hammad H, Otsuki Y. Involvement of fas system and active caspases in apoptotic signally in testicular germ cellsof ethanoltreated rats. Int J Androl 2002; 25:159-67.

14. Florek E, Marszalek A. An experimental study of the influences of tobacco smoke on fertility and reproduction. Hum Exp Toxicol 1999; 18: 272-8. doi:10.1191/096032799678840039.

15. Villalta J, Ballesca JL, Nicolas JM, Martinez de Osaba MJ, Antunez E, et al. Testicular function inasymptomatic chronic alcoholics: relation to ethanol intake. Alcohol Clin Exp Res 1997; 21:128-33.

16. Gomes IC, Cagnon VH, Carvalho CA, Luca IM. Stereology and ultrastructure of the seminal vesicle of $\mathrm{C} 57 / \mathrm{BL} / 6 \mathrm{~J}$ mice following chronic alcohol ingestion. Tissue Cell 2002; 34:177-86. doi: 10.1016/S00408166(02)00029-0.

17. Favaro WJ, Cagnon VH. Immunolocalization of androgen and oestrogen receptors in the ventral lobe of Rat prostate after long term treatment with ethanol and nicotine. Int J Androl 2008; 31: 609-18. doi: 10.1111/j.13652605.2007.00817.x.

18. Particia VT. The calam/acmal standards of veterinary care and laboratory animal welfare. Can Vet J 2008; 49: 86-8.

19. Elsokkary GH. Quantitative study on the effects of chronic ethanol administration the testis of adult male Rats. Neuroendocrinol Lett 2001; 22: 93-9.

20. Zhu Q, Meisinger J, Emanuele NV, Emanuele MA, Lapaglia N, Thiel DH. Ethanol exposure enhances apoptosis within the testes. Alcohol Clin Exp Res 2000; 24: 1550-6.

21.Neaves WB, Johnson L, Porter JC, Parker CR JR, Petty CS. Leydig cell numbers daily sperm production and serum gonadotropin levels in aging men. J Clin Endocrinol Metab 1984; 55: 756-63. doi: 10.1210/jcem-59-4-756

22.Han MS, Lim YM, Quan W, Kim JR, Chung KW, Kang M, et al. Lysophosphatidyl choline as an effector of fatty acid induced insulin resistance. J Lipid 
Res 2001; 52:1234-46. doi: 10.1194/jlr.M014787.

23.Chung BH, Mitchell SH, Zhang JS, Young CY. Effect of decosahexaenoic and eicosapentaenoic acid on androgen mediated cell growth and gene expression in LNCap prostate cancer cells. Orcinogenesis 2001; 22: 1201-06.

24.kilgour RJ, Pisselet C, Dubois MP, Courot M. Ram Lambs need FSH, LH for normal testicular growth. Sertoli cell number and onest of spermatogenesis. Reprod Nutr Dev 1998; 38: 539-50.

25.Ling T, Liao S. Inhibition of steroid 5alpha -reductase by specific alphatic unsaturated fatty acids. Biochem J 1992; 282: 557-62.

26.Rahman AHMM, Anisuzzaman M, Ferdousahmed A, Rafiul AKM, Naderuzzaman ATM. Study of nutritive value and medicinal uses of cultivated cucurbits. J Appl Sci Res Bangladesh 2008; 4: 555-08.
27. Soonlerichard $\mathrm{M}$, Catherine $\mathrm{R}$. Anatomical and functional evidence for a nearal hypothalamictesticular pathway that is independent of the pituitary. Endocrinology 2002; 143: 4445-50. doi: 10.1210/en.2002-220392

28. Lafuente A, Marquez N, Perezlorenzo M, Pazo D, Esquifino AI. Cadmium effects on hypothalamic- pituitary- testicular axis in male Rats. Exp Biol Med 2001; 226: 605-11.

29. Vooqt PA, de Besten PJ, Kusters GC, Messing MW. Effect of cadmium and zinc steroid level in the sea star Asterias rubens L. Comp Biochem Physiol 1987; 86: 8309.

30.Giovenakazawa RA. Traditional medicine in the treatment of enteroparasitosis Spanish. Rev Gastroenterol Peru 1996; 16:197-202. 


\title{
Histological Evaluation of the Effect of Cucurbita pepo L. fruit on Seminiferous Tubules induced by Ethanol Administration in Rats
}

\author{
Esfandiari $A^{l^{*}}$, Ghaedi $H^{l}$
}

(Received: June 14, 2017

Accepted: August 28, 2017)

\begin{abstract}
Introduction: According to previous research, Cucurbita pepo L. increases sex hormones in males. The purpose of this study was to survey the effect of Cucurbita pepo on the histomorphometrical changes of testes induced by ethanol administration in male Wistar rats.
\end{abstract}

Materials \& Methods: Twenty male Wistar rats were divided into four groups of five as follows: 1- Control group, 2- Experimental group1 (received $20 \%$ ethanol $[1 \mathrm{mg} / \mathrm{gr}$, i.p.] for 30 days), 3- Experimental group2 (received 20\% ethanol [1 mg/gr, i.p.] along with Cucurbita pepo as $20 \%$ of their meal for 30 days), and 4- Experimental group3 (received $20 \%$ ethanol $(1 \mathrm{mg} / \mathrm{gr}$, i.p.) along with Cucurbita pepo as $80 \%$ of their meal for 30 days).

Findings: Results showed that seminiferous tubule wall thickness, weight of the testes, and the number of spermatogenic cells were decreased in the Experimental group1.

\begin{abstract}
However, all these parameters were increased in the Experimental group3 compared to the Experimental group1. These reductions in the Experimental group1 in comparison with the control group were significantly different. However, all these parameters had increased in the Experimental group3 compared to the control group with no significant difference, while they were significantly different from experimental groups 1 and 2 .
\end{abstract}

Discusion \& Conclusions: It is concluded that high doses of Cucurbita pepo (80\%) may prevent reduced number of spermatogenic cells caused by the consumption of alcohol. However, low doses of Cucurbita pepo (20\%) cannot impede the destructive effects of alcohol.

Keywords: Cucurbita pepo L., Ethanol, Histomorphometric, Rat

1.Dept of Basic Sciences, Faculty of Veterinary Medicine, Kazerun Branch, Islamic Azad University, Kazerun, Iran

*Corresponding author Email: Esfandiari.arash@gmail.com 